\title{
الإعجاز اللغوي والإعجاز العلمي لألفاظ القرآن الكريم
}

\author{
أدرياني يوليزار، الماجستير \\ كلية أصول الدين من جامعة أنتاساري الإسلامية الحكومية
}

Diterima tanggal 05 Juli 2017 / Disetujui tanggal 20 Juli 2017

\section{ملحَّص}

وكان من العلماء من يجصر أسماء كثيرة للقرآن، وبعضهم من يرى أن الأسماء منحصرة بما اشتهرت بين العلماء والباقية منها هي صفات للقرآن. والقرآن الكريم معجز في كل شيء، معجز قديما ومعجز حديثا، ومعجز لاحقا، ومعجز إلى قيام الساعة. وهناك بعض شواهد إعجاز القرآن في ألفاظه وي معانيه وما يحتويه من علوم وحقائق لا تحصى ويعترفها العلماء في مختلف مجالات العلوم الإنسانية.

\section{المقدمة : معنى القرآن ومعنى الإعجاز

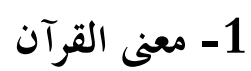

القرآن في اللغة مصدر مرادف للقراءة، ثم نقل من معناه اللغوي إلى معناه الاصطلاحي الدال

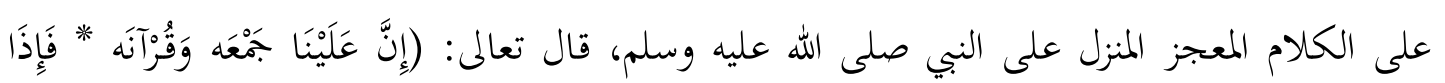

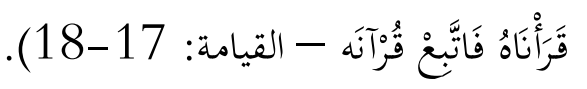

وقال آخرون: القرآن اسم غير مشتق من شيء وهو اسم خاص بكلام الله مثل التوراة

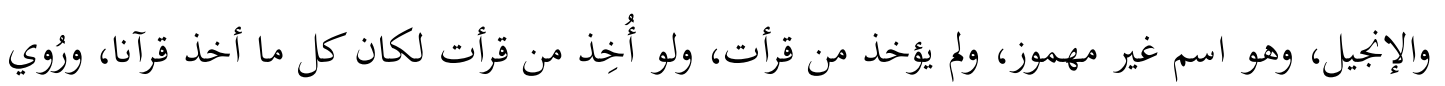

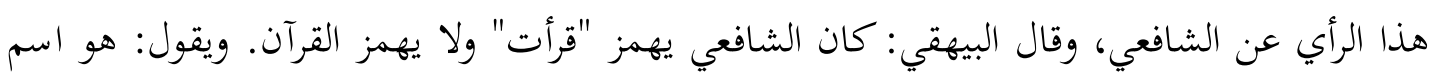
لكتاب الله غير مهموز، قال الواحدي: قول الشافعي أنه اسم لكتاب الله، يعني أنه اسم غير مشتق. وقال آخرون: أنه مشتق من قرنت الشيء بالشيء إذا ضممثُه إليه فسمَّى بذلك القرآن السور والآيات والحروف فيه، ومنه قيل للجمع بين الحج والعمرة قران، قال: وإلى هذا المعنى ذهب الأشعري. وقال القرطبي: القرآن بغير همز مأخوذ من القرائن لأن الآيات منه يصدق بعضها بعضا ويشابه بعضها بعضا، فهي حينئ قرائن. قال الزجاج: هذا القول سهو، والصحيح: أن ترك الهمز فيه من باب التخفيف ونقل حركة الهمزة إلى الساكن قبلها، وهذا ما أشار إليه الفارسي في الحلبيات. 
وتوسّع علماء التفسير في توضيح الأسماء التي سمّيّي بها القرآن الكريم. قال الفارسي في معنى

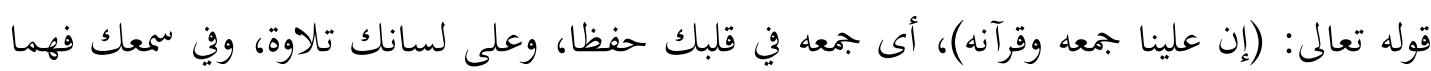
وعلما. وأما الكلام فمشتق من التأثير، يقال: كلّمه إذا أثّر فيه بالجرح، فسمي الكلام كلاما، لأنه

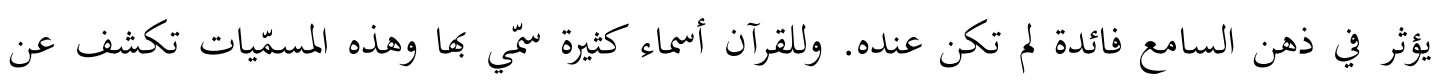
الوظائف والآثار الحسنة لهذا الكتاب الكريم. أما "النور" فلأنه يدرَك به غوامض الحلال والحاب الحرام، وأما تسميته "هدى" فلألنه فيه دلالة بينة

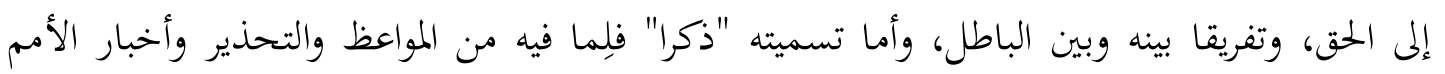
الماضية، وهو مصدر ذكرت ذكرا.

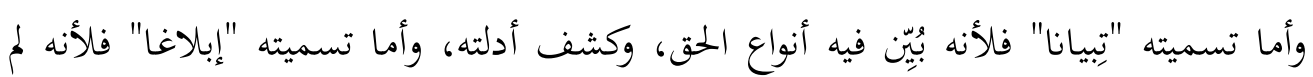

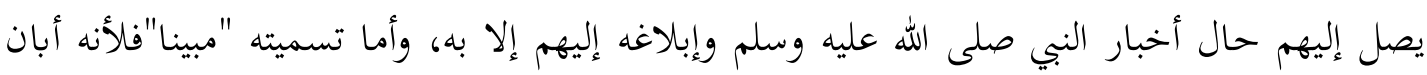

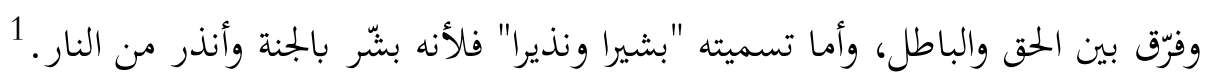

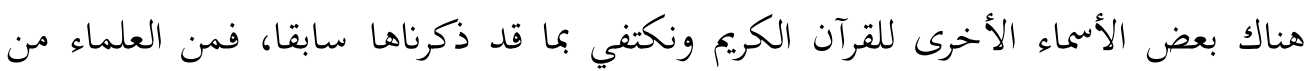

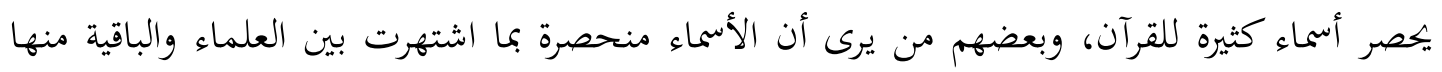
هي صفات للقرآن. فالصفات تدل على مكانة القرآن الكريم ووظائفه. 2- معنى الإعجاز الإعجاز مصدر من كلمة أَعْجزَ - يُعْجزز - إعجازا - فهو مُعجِز لصيغة الفاعل. أما المعجزة هي أمر خارق للعادة مقرون بالتحدي سالم عن المعارضة وهي إما حسية إما عقلية. 2

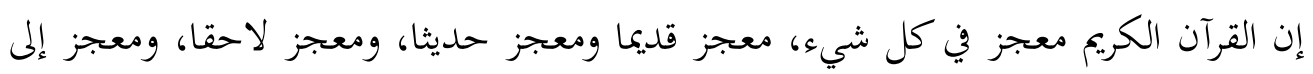

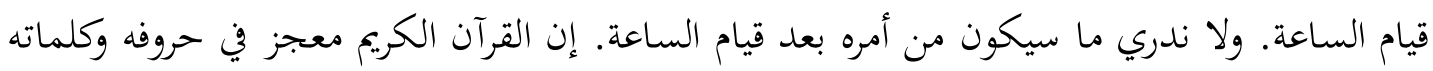

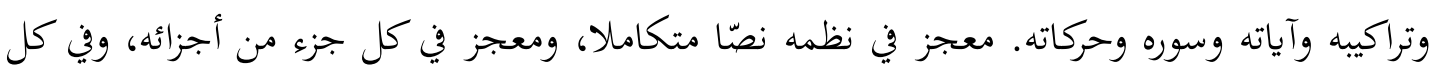
دلالة من دلالته (عودة خليل أبو عودة، 1995م : 29). القرآن الكريم هو كلام الله رب العالمين، نزل به الروح الأمين على خلى خاتم الأنبياء والمرسلين نبينا

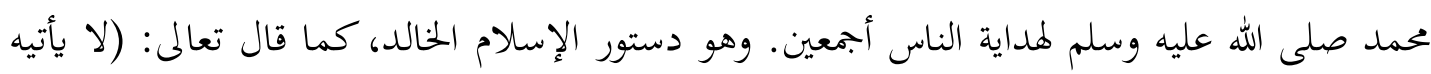

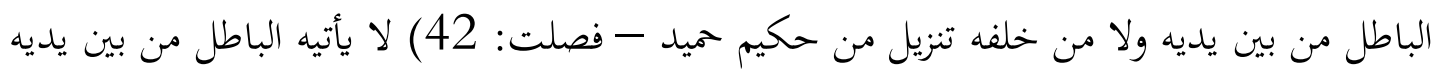

1 عبد القادر محمد صالح، الثنسير والمفسرون في العصر الحديث (حلب: دار المعرفة، الطبعة الأولى، 1424هـ/2003م)، 17- 
يعني لا يستطيع أن يزيد عليه، ولا من خلفه يعني لا يستطيع أحد أن ينقص منه ولو حرفا. وهذا لأن

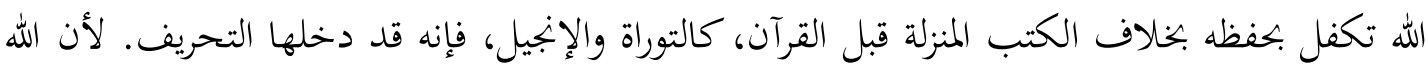

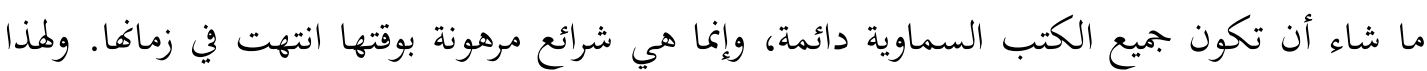

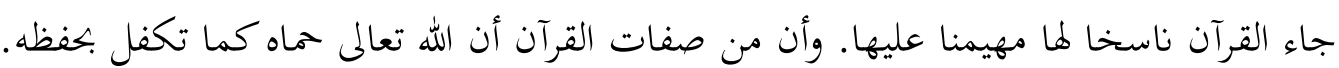

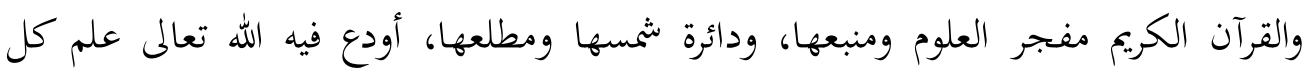

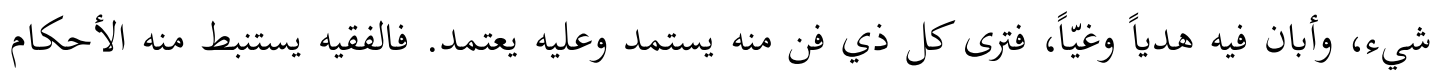

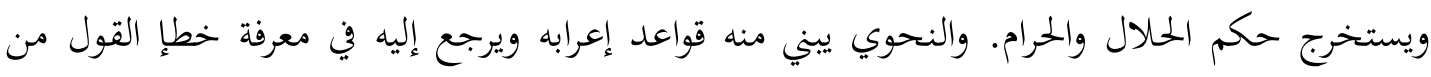

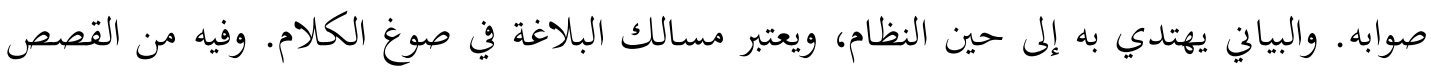

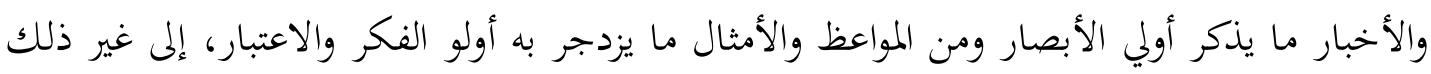
من علوم لا يقدر قدرها إلا من علم حصرها.

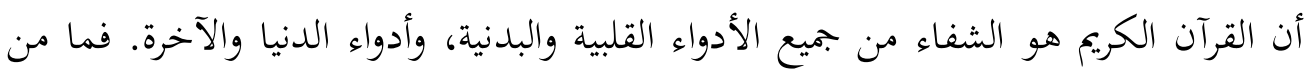

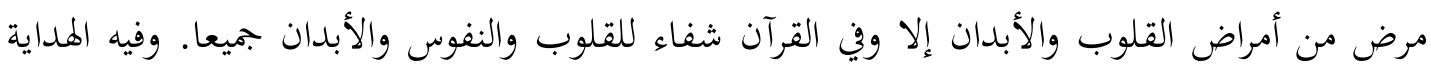

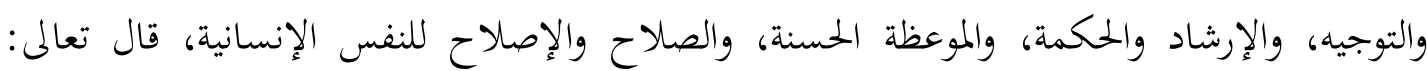

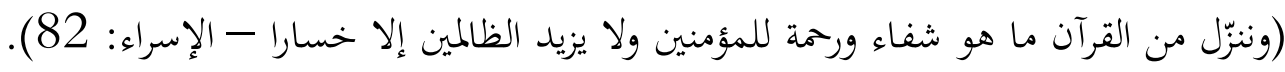

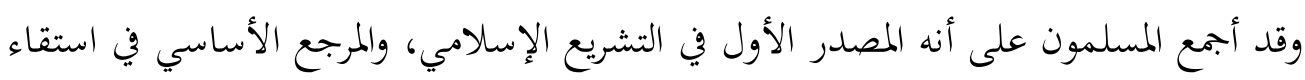

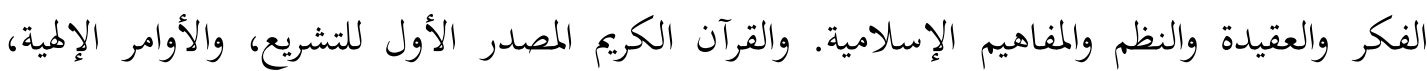

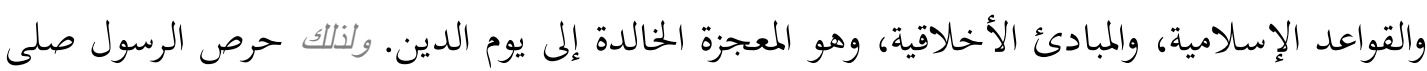

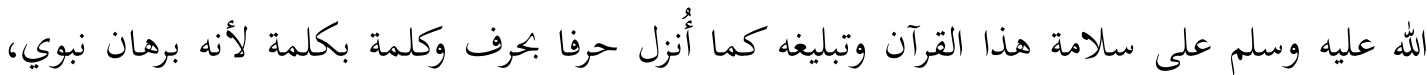

$$
\text { ومعجزة الإسلام الخالدة. } 3
$$

\section{القرآن معجزة باقية إلى قيام الساعة}

ونبينا محمد صلى الله عليه وسلم لاببي بعده، هذه ألف وأربعمائة عام قد مرت ما جاء إعه رسول،

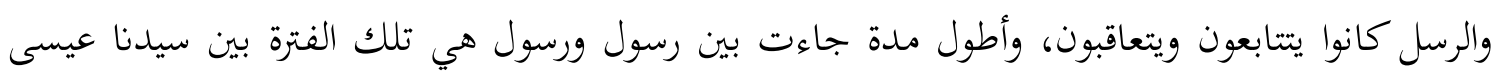

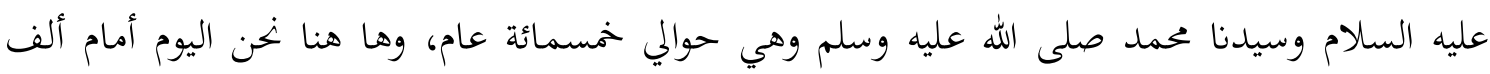

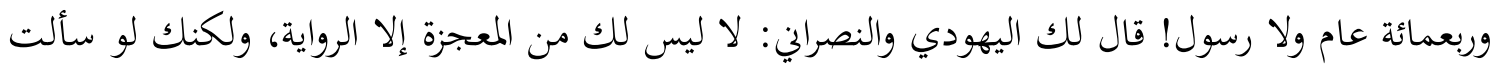

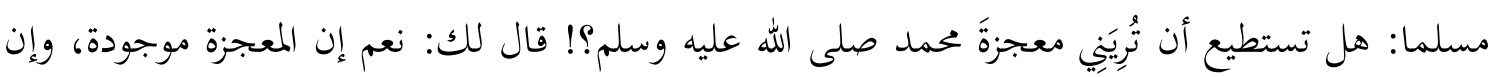


البينة حاضرة مستمرة وباقية إلى قيام الساعة، إها القرآن العظيم، (قل أي شيء أكبر شهادة قل الله شهيد بيني وبينكم وأوحى إلي هذا القرآن لأنذركم به ومن بلغ - الأنعام: 19) جعل الله البينة في القرآن منه شاهدة على صدقه، وجعل الرسالة وجعل البية شيئا واحدا، وكانت الرسالة من قبل شيئا، والمعجزة شيئا آخر، فشاء الله جلّ وعلا أن يجمع محمد صلى الله عليه وسلم بين الرسالة والمعجزة في آن واحد، فالقرآن فيه الحلال والحرام، فيه البيان والهدى، وفيه المعجزة، والدليل على صدقه ويتلوه شاهد منه، هذا كتاب الله بين أيدينا، فكيف نعرف أنه من عند الله؟ جعل الله العلامات الكثيرة الدالة على أنه من عنده في فصاحته وبلاغته، وفي تركيب ألفاظه بينات تدل على أن هذا اللفظ جاء من عند الله، وفي علمه الذي احتوى عليه هذا اللفظ واحتوت عليه تلك التراكيب، والآيات ما يدل على أن المصدر من عند الله جل علا، قال تعالى: (لكن الله يشهد بما أنزل إليك أنزله بعلمه - النساء: 166) أى أنزله وفيه علمه. فالقرآن العظيم يحمل العلم الإلهي فيه، ويدل على يلى أنه من عند الله، وكل آية من كتاب الله تحمل علما في بابها وفي مجالها، إذا ارتقى علم الإنسان إلى ذلك

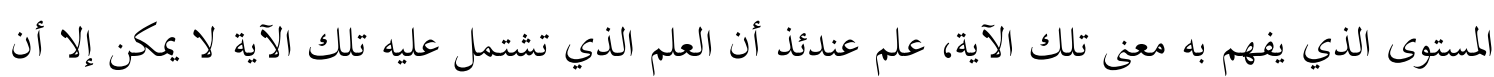
يكون من عند الله سبحانه وتعالى. فالقرآن كنز لا يفنى، ولما كان الناس لا يستطيعون أن يهيطوا بعلم الله، (ولا يهيطون بشيء من

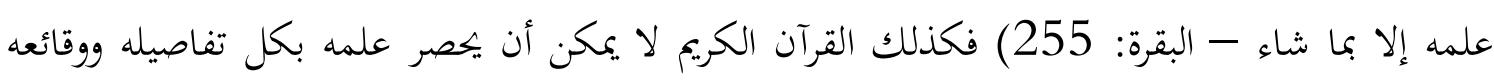
في جيل من الأجيال، بل هو باب مفتوح، وبحر زاخر لا يشبع منه العلماء، ولا تنقضي عجائبه، ولا يبلى لهاء

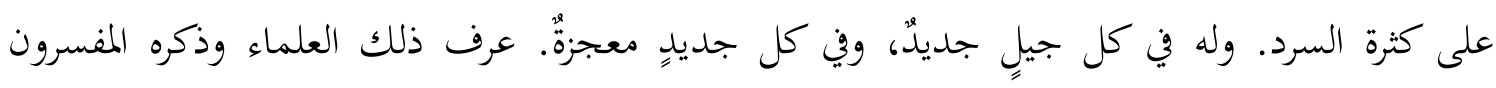
وحرروه وبينوه عند شرح الله جل علا (ولتعلمُنّ نبأه بعد حين - ص : 88) وعند قول الله سبحانه وتعالى: (لكل نبإ مستقرٌّ وسوف تعلمون - الأنعام: 67) وعند قوله تعالى: (وقل الحمد لله سيريكم آياته فتعرفوها - النمل: 93) وعند قوله تعالى: (سنريهم آياتنا في الآفاق وفي أنفسهم حتى يتبين لهم أنه الحق - فصلت:

فهذه كلها تدل على أن القرآن باقٍ إلى يوم القيامة، وتدل على ختام الرسل، فنبينا محمد صلى الله عليه وسلم خاتم الأنبياء والمرسلين، والقرآن دليل على ذلك، فلا يدخله تحريف أو تحويل من زيادة أو نقصان. بل إنه باقٍ منذ نزوله إلى يوم الدين، لأن الله قد تكفّل ووعد بحفظه ورعايته.

4 عبد المجيد الزنداني، الشيخ، رسائل العلم والإيمان ودلائل الإعجاز في السنة والقرآن، آيات الله في الآفاق (القاهرة: مكتبة القرآن، 


\section{بعض شواهد الإعجاز اللغوي والعلمي لألفاظ القرآن الكريم}

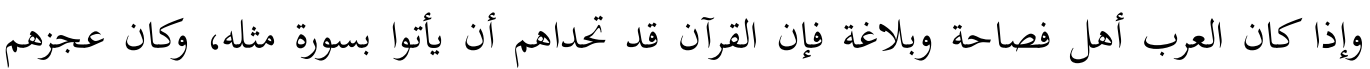

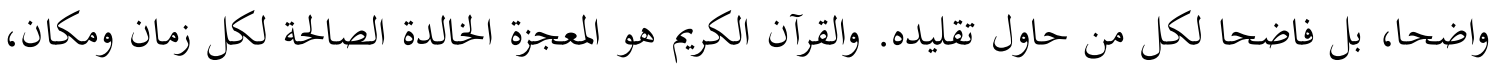
ومن أجل هذا كان عطاؤه متجددا على مر العصور. ففي عصر العلم يرى العلماء آيات الله في الآفاق وفي أنفسهم ، حهود هتى يتبين لهم أن القرآن الكريم

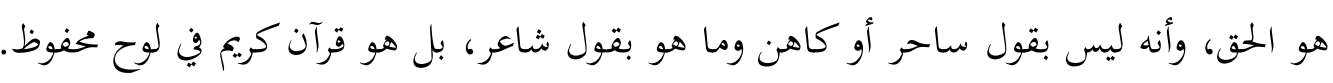

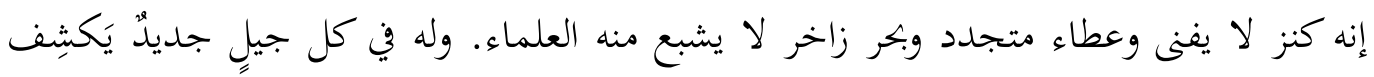

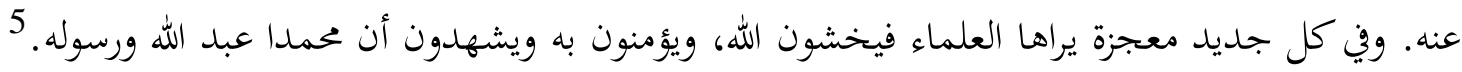

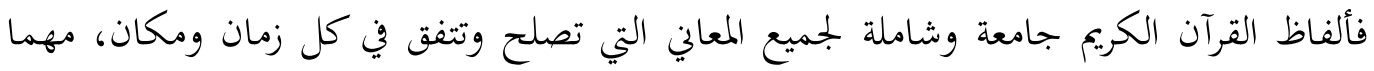
تغيرت وتطورت دلالات الألفاظ العربية في مرور الزمان. فالتغير الدلالي (semantic change) مصطلح من فئي

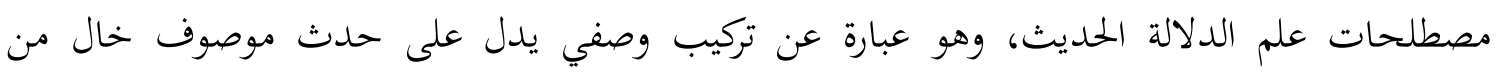

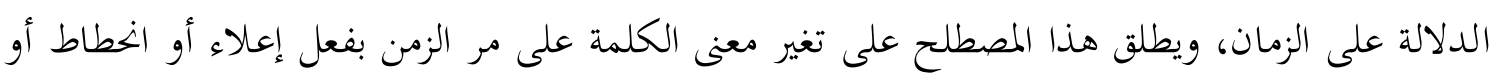
توسع أو الخسار أو مجاز أو نحو ذلك. وما يتعلق بأسباب التغير الدلالي بتحتمع عدة أسباب على الكلمة، فتؤدي إلى تغيير دلالتها، هذه

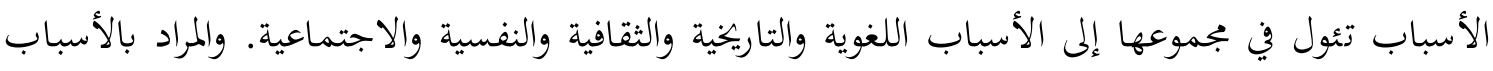

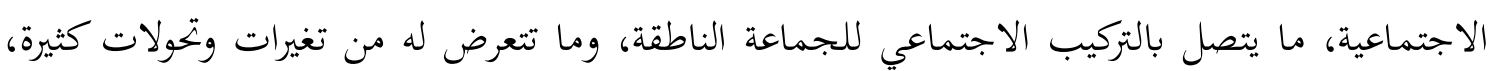

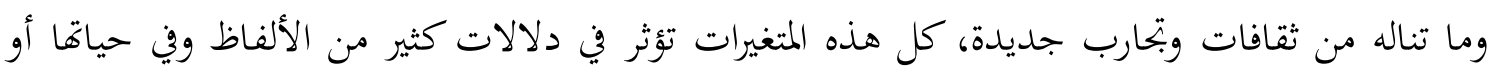

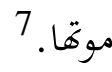

والتطور في اللغة أمر حتمي يشبه أن يكون وجها من وجوه تطور الحياة نفسها. وهو في معناه

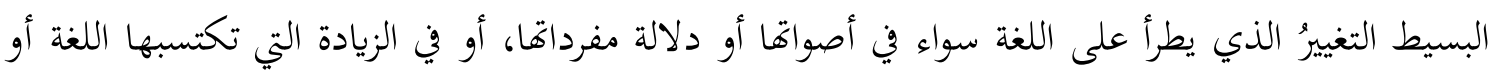

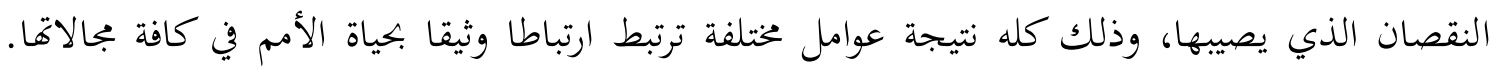
وليس من شك أن التطور اللغوي مرتبط بسنن التطور العام في حياة الإنسان. واللغة ظاهرة اجتماعية تتأثر

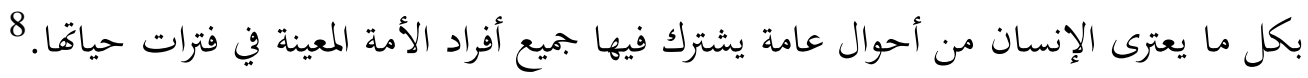

5 عبد الجيد الزنداني، الشيخ، رسائل العلم والإيمان ودلائل الإعجاز في السنة والقرآن، آيات الله في الآفاق، 5.

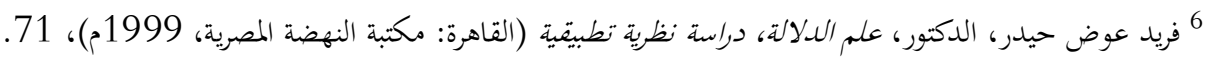

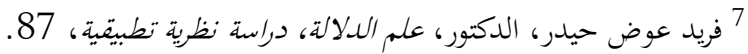
8 عودة خليل أبو عودة، الدكتور، شواهد في الإعجاز القرآني، دراسة لغوية ودلالية العالية (عمان: المكتبة الوطنية، الطبعة الأولى، 
فالقرآن الكريم معجز في ألفاظه وفي معانيه وفي سياقاته وفي كل الجوانب مما يتصل بجوانب الحياة الدنيوية والأخروية. فهناك بعض شواهد إعجاز القرآن في ألفاظه وفي معانيه وما يحتويه من علوم وحقائق لا تحصى. فالشواهد لإعجاز القرآن الكريم كثيرة متعددة، ولنذكر بعض الشواهد من الاكتشافات العلمية من بعض بجالات العلوم، فمنها ما يلي:

1 - 1 - 1 القرآ شفاء ورحمة

الدكتور أحمد القاضي له اكتشافات أخرى في مجال الإعجاز في لفظ القرآن في التراكيب اللفظية، قرأ قوله تعالى: (وننزل من القرآن ما هو شفاء ورحمة للمؤمنين - الإسراء : 82) قال: سأختبر أثر القرآن في الذين عندهم "توتر عصبي" وقد رأيت في الأسئلة سؤالا عن علاج التوتر العصبي - جاءنا سؤال يقول: ما هو العلاج الإسلامي لمن عنده ضيق نفس وتوتر عصبي؟ فأقول الجواب قدمه لنا الدكتور أحمد القاضي في أمريكا. جاءنا بمرضى بالتوتر العصبي من المسلمين ومن غير المسلمين. التوتر العصبي يصاحبه ظواهر في البدن، ظواهر تثوثر على سرعة التيار الكهربائي في العضلات، وتؤثر على درجة حرارة الجلد، وتؤثر على عدد نبضات القلب، فإذا كان الإنسان عنده توتر عصبي، وضيق في نفسه، ضيق "متضايق"، فإن ذلك ينعكس على بدنه بهذه الظواهر. الدكتور أحمد القاضي جاء بجهاز يقيس "سرعة التيار الكهربائي" في الجلد والعضلات ويقيس كذلك "درجة الحرارة" في الجلد، أجهزة الكترونية، استعملها لهذه الأغراض ويقيس عدد نبضات القلب. إذاً الحالة النفسية أثرت على الحالة البدنية!. إنه جاء بأجهزة تقيس حالة البدن، ثم جاء بكومبيوتر - حاسب آلي - وغذاه بهذه المعلومات، بحيث ينتهي في النهاية إلى شاشة، هذه الشاشة تبين وتعكس التوتر النفسي في الإنسان، فإن كان عنده توتر نفسي صعد الخط، صعد المؤشر. إذا بدأ ينخفض الخفض المؤشر، جاء بمجموعة من المسلمين عندهم توتر عصبي وضيق نفسي، وقلق واضطرابات، فأدخلهم غرفة فيها صمت كامل....سكوت! ثم رأى القراءة على الشاشة ما تغير شيء! التوتر كما هو، فأدخلهم غرفة أخرى فيها تلاوة القرآن، وشرح لهم بعض معاني آيات القرآن التي يسمعوفا فلما استمعوا للقرآن الكريم بدأ المؤشر ينخفض، ويدل على أن التوتر العصبي بدأ يتناقص، وينزل عند قراءة القرآن. ربما يقول قائل: إن السبب في ذلك هو لغة العرب، فيها جمال وفيها ألفاظ جميلة تؤثر على ولى النفس الإنسانية، فجاء وأدخل هذه المجموعة غرفة أخرى ليُقْرَأ عليهم أبياتا شعرية باللغة العربية أبياتا

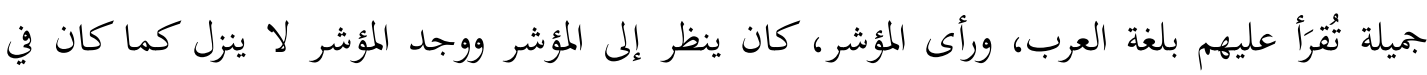
حالة القرآن، فقال: قد يقول قائل إن التجويد الذي في القرآن صَحِبَتْه موسيقى وإيقاع، وهذه الموسيقى والإيقاع أثرت على السامع، فقالوا: نأتي بلغة العرب، ونجوّد هذه المقطوعات الشعرية بتويدا 
فجوّدوا تلك المقطوعات، جوّدوا تلك القطع النثرية فوجدوا المؤشر لا يعطي نفس الدلالة التي يشير

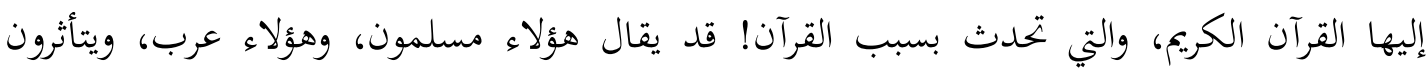

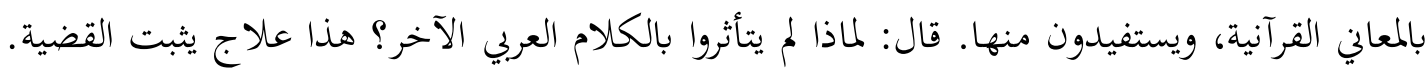

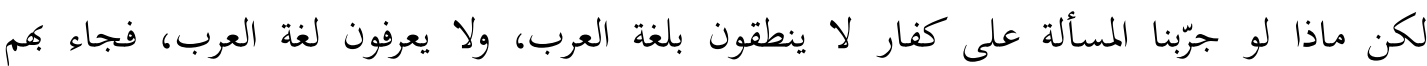

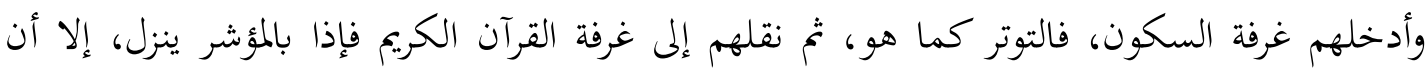

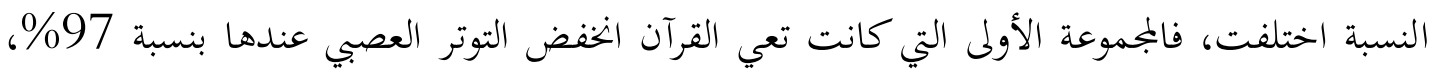

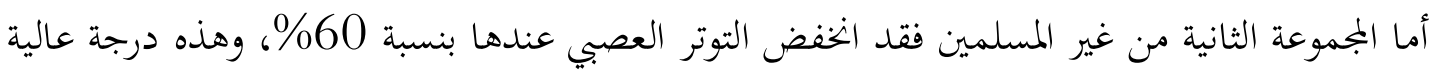

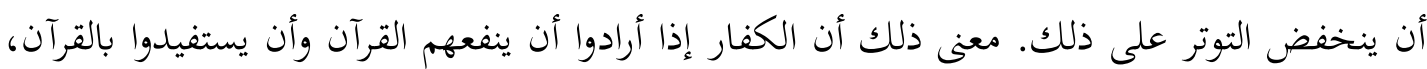

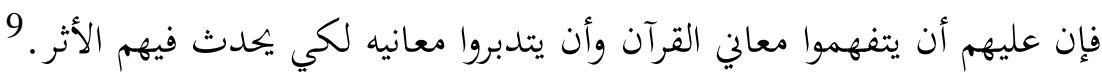

2- 2 دراسة لكمية الغذاء من البروتينات

أما الدكتور "المعايرجي" في جامعة قطرونيات فئه فيقول: لقد درست كميات الغذاء من "البروتينات"

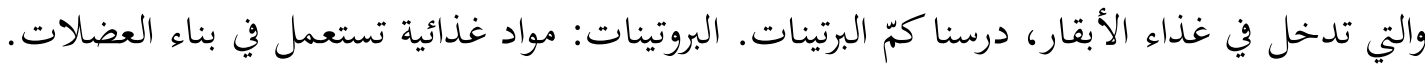

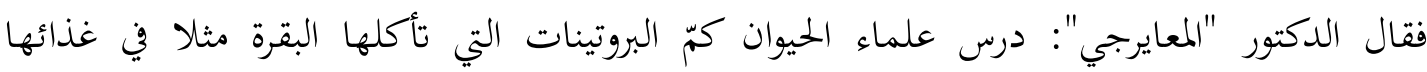

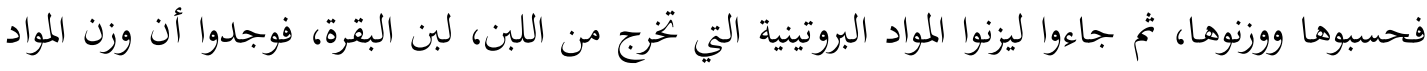

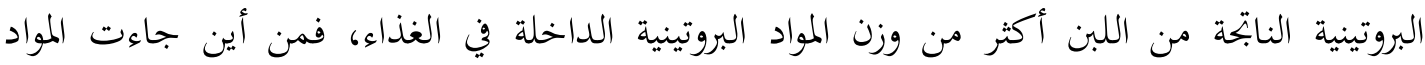

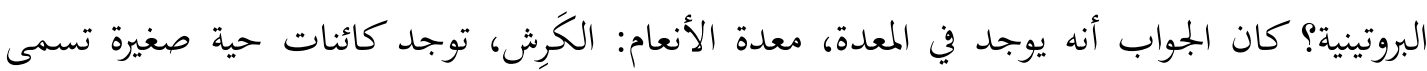

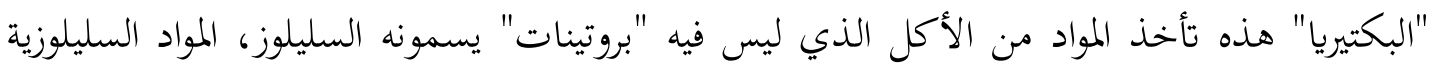

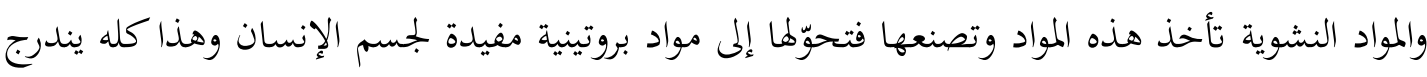

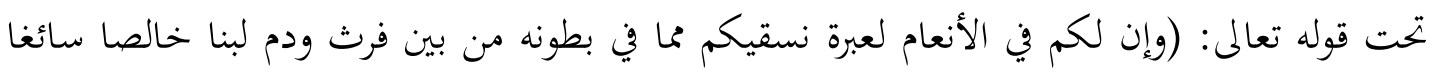

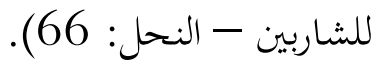
وقد جاء بحث آخر لطبيب آخر، يدرس القيمة الغذائية للبن ويقارن بين القيمة الغذائية للبن

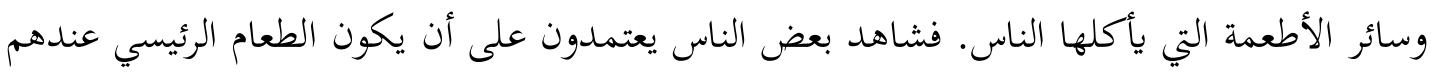

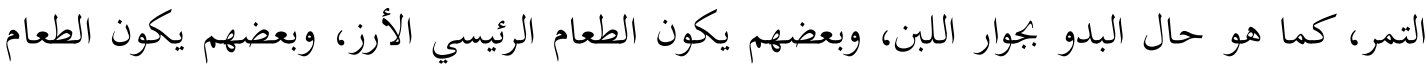

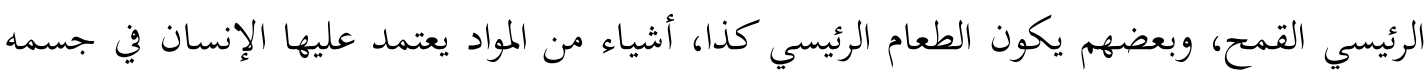

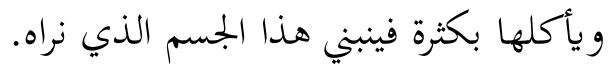


وعندما درس الإنسان أي الأغذية أعلى، وأرفع قيمة غذائية ما هو أحسن غذاء توجد فيه جميع المواد اللازمة لجسم الإنسان؟ بعد أن تقدمت وسائل الاكتشافات والتحاليل لمعرفة المواد الغذائية وتصنيفها قام طبيب بهذه الدراسة، فكانت التيجة أن اللبن هو أغنى غذاء وأحسن غذاء وأكمل غذاء يحتاجه جسم الإنسان، أكمل غذاء للأطفال وللشباب وللرجال وللشيوخ، فيه جميع المواد الغذائية، ولا يوجد غذاء يجزى عن اللبن، يجزى عن الطعام الشراب سوى اللبن. قال هذا الطبيب - جزاه الله خيرا - الدكتور علي أحمد الشحات قال: هيا لنقرأ حديث الرسول صلى الله عليه وسلميكشف لنا هذا السر ويبيّنه لنا قبل أن يعرفه الناس، قال عليه الصلاة والسلام: (من أطعمه الله طعاما فليقل اللهم بارك لنا فيه وارزقنا خيرا منه) أي جميع الأطعمة هناك ما هو خير منها - بقية الحديث (ومن سقاه الله لبنا فليقل اللهم بارك لنا فيه وزدنا منه). فهناك (ارزقنا خيرا منه)، وهنا (بارك لنا فيه وزدنا منه) ليس هناك شيء أحسن منه، ثم يكشف الرسول صلى الله عليه وسلم السر فيقول: (فإني لا أعلم ما بيجزى من الطعام والشراب إلا اللبن - أخرجه أحمد في مسنده، وابن سعد في طبقاته، وقال الترهذي: هذا حديث حسن، جمع الجوامع، الجزء الثالث)، (فإني لا أعلم ما يجزى) أي: ما يغني عن طعامي وشرابي إلا اللبن.

\section{3- التحليل اللغوي والعلمي للدكتور هللي برانت}

وتوقف الدكتور هللي برانت عند لفظ واحد في هذه الآية وقدم بحثا عنه حوله وحول غيره. هذا اللفظ قوله تعالى: (الله الذي يرسل الرياح فتثير سحابا)، فتثير سحابا، ما معنى لفظ: "ثثير"؟ قال: لفظ تثير، إذا رجعنا إليه في لغة العرب هكذا أبحاث الإعجاز العلمي بل هكذا أبحاث التفسير، لا بد لد له لكي تفهم معنى اللفظ أن ترجع إلى معناه المستعمل وقت نزول القرآن على نبينا محمد صلى الله عليه وسلم. فما معنى لفظ تثير؟ إذا رجعت إلى قواميس اللغة العربية تجد "تثير" تأتي بمعنيين: بمعنى أظهر، والإظهار أن تظهر شيئا لم يكن ظاهرا، وهذا مستعمل للآن عندنا في لغتنا نقول: أثارَ مشكلةً، فمل معنى أثار مشكلة؟ يعني أظهر مشكلة لم تكن موجودة فأظهرها، "ويعمل لنا مشكلة" و "أثار مشكلة" بمعنى أظهر. المعنى الثاني في لفظ أثار أها التهييج، من هيج الشيء، فيقال: لا تثرين أى لا كيجني. إذاً لفظ أثار يأتي بمعنيين: أى الإظهار والإثارة.

هل هناك علاقة للرياح بالسحاب؟ هيا بنا نرى ما وصل إليه علماء الأرصاد في علاقة الرياح بالسحاب. هذا موضوع دراسة لو رأيتم الخيالات عند الأمم السابقة. كيف كانوا يتصورون العلاقة بين الرياح والسحاب؟ كيف يتصورون الطقس؟ وعندي صور وشرائح تبين أن بعض الأمم...اليونان مثلا 
كانوا يعتقدون أن الرياح هذه هناك آلهة معها بوق تنفخ فيه، فإذا نفخت طلعت الرياح، وإذا غضبت أنزلت عليهم مطرا يغرقهم.

والذين كانوا يسكنون في الرافدين - أهل حضارة الرافدين كانوا يتصورون أن هناك

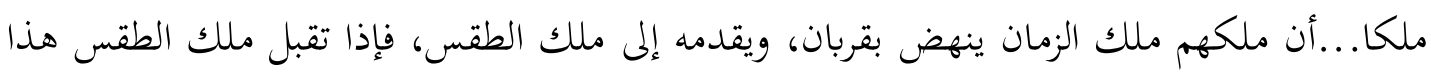

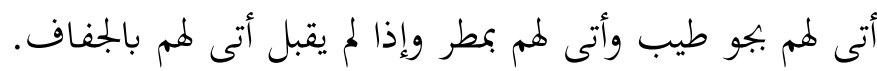

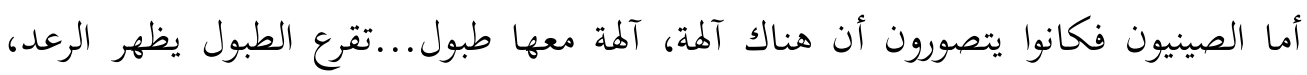

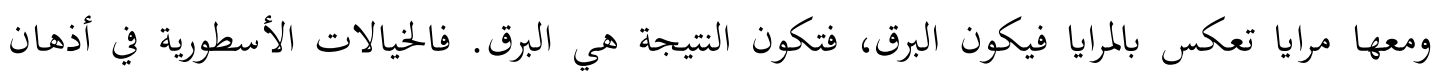

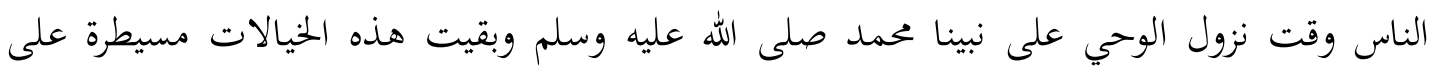

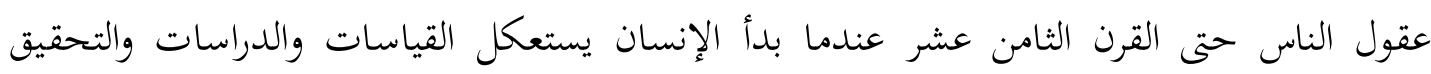

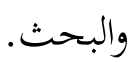

أنت ترى في بعض الأحيان رياحا بدون سحاب، وترى سحابا بدون رياح، وترى رياحا تحرك

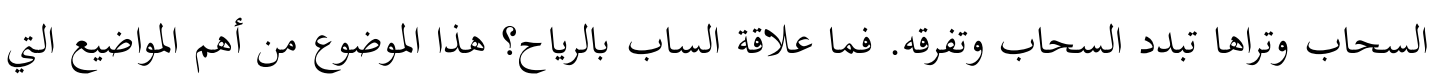
يدرسها علماء الأرصاد فوجدوا م يلي:

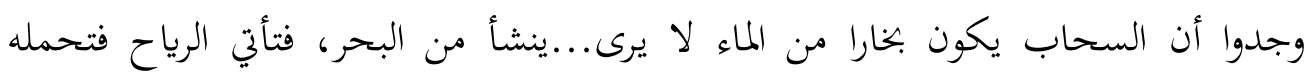

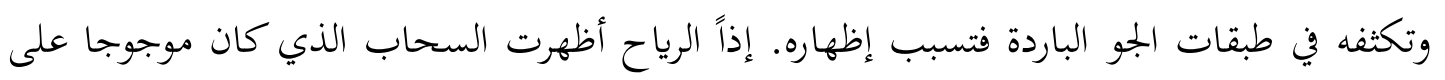

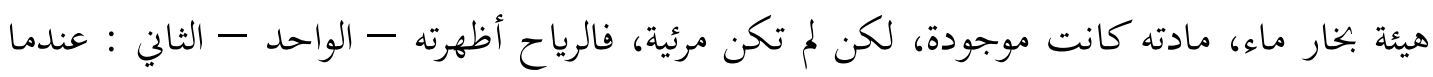

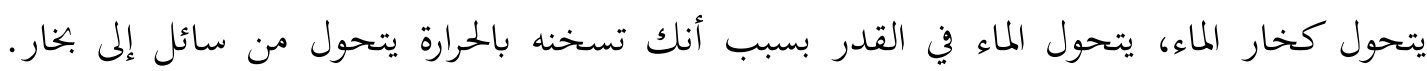

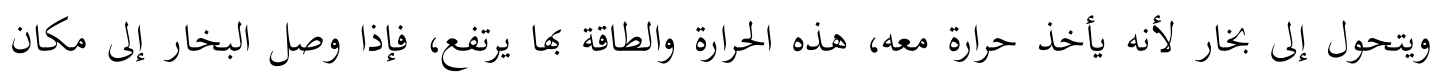

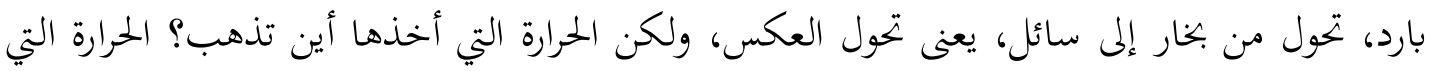

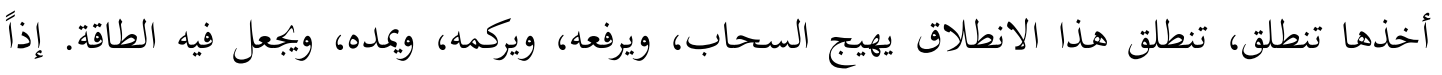

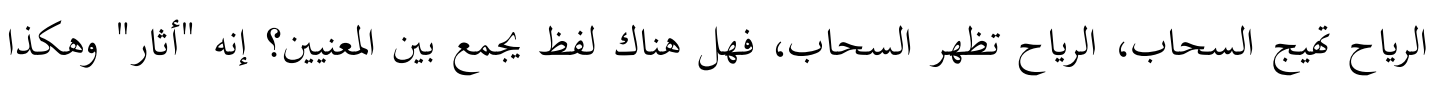

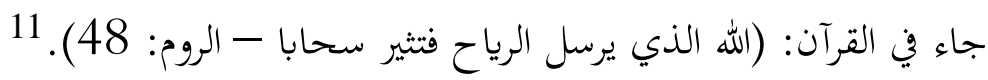

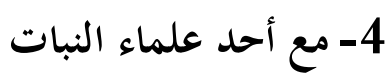
أحد علماء النبات تقدم بوصف جميل جاء في كتاب الله الكريم في وصف الصحابة - رضوان

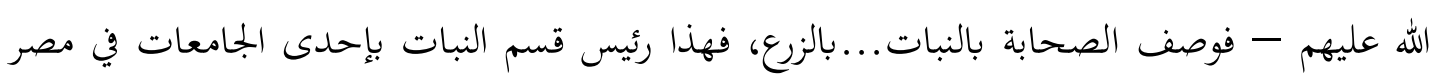

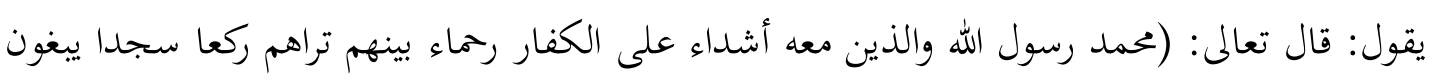


فضلا من الله ورضوانا سيماهم في وجوهةم من أثر السجود ذلك مثلهم في التوراة ومثلهم في الإنجيل كزرع أخرج شطأه فآزره فاستغلظ فاستوى على سوقه يعجب الزراع ليغيظ بهم الكفار - الفتح: 29). يقول: مثلهم في الإنجيل أفم كزرع، وعلماء التفسير تتبعوا ما في الأناجيل فبينوا أن في الأناجيل خبرا بأن أمة ستأتي ستنبت كالزرع ع نبي وتأتي بعدهم تنبت كالزرع. المهم تعالوا إلى التشبيه الذي شبه نبينا محمدا صلى الله عليه وسلم والصحابة فقال: (ومثلهم في الإنجيل كزرع أخرج شطاه)، الشطء: هو الفرخ مثل الدجاج تخرج فراخا، هذا أيضا يخرج فراخا، فراخ زرع يسميه علماء النبات فراخا، وعلماء التفسير يسمونه فرخا. لماذا؟ لأن هذا الفراخ يتحول إلى زرع مستقل. فقال هذا الدكتور، هذا يحدثنا عن النباتات النجيلية من العائلة النجيلية. نباتات العائلة النجيلية هي البُر والأُرز وقصب السكر والشعير وما شاههما. قال هذا الزرع كزرع أخرج شطأه، هذا هو الزرع الذي يخرج الأشطاء، الفراخ هذه، قال إذا نبتت الحبة وظهر الزرع. عندما ينمو الزرع يبدأ يخرج الفرخ من إبط الأوراق فيخرج الفرخ من الزرع، لا من الحبة لذلك قال تعالى: (كزرع أخرج شطاه)، ثم قال في السنوات الأخيرة بعد الثلاثينات، درس العلماء من أين يأتي الغذاء لهذا الشطء عندما يخرج، من أين؟ فوجدوا أنه يأتيه ويصنع له من الزرع نفسه، فالزرع يؤازره ويمده بالغذاء (كزرع أخرج شطأه آزره) فلما آزره، تأتي عملية أخرى فتكون عُعَدًا، عقدا تحت آباط الأشجار، الزروع، يكوّن عقدا متقاربة فاستغلظ هذذه العقد، فاستوى، المسافة بين العقدة والعقدة تستطيل حتى مسافة عالية، فاستوى على سوقه يُعجب الزراع ليغيظ به الكفار - قال: وهذه هي النباتات - النجيلية، يبدأ النبات يخرج من الزرع ويؤزره الزرع ويستغلظ ويستوي على سوقه، ويثمر، ويعجب الزراع ليغيظ بهم الكفار. بهذه المناسبة لهذه الآية قال الإمام مالك رضي الله عنه: من أصابه الغيظ من الصحابة، من أصبح وفي قلبه غيظ على الصحابة فقد أصابته هذه الآية، لأن هذه الآية ماذا تقول؟ ليغيظ بكم الكفار، فالذين يغتاظون من الصحابة وقعوا في هذا الوصف، وصف الكفار. فيحذر الإمام مالك أولئك الذين يغتاظون، ويغيظهم الصحابة - رضوان الله عليهم - فقال من أصبح في قلبه غيظ على الصحابة فقد أصابته هذه الآية. 12

\section{5- 5لماء الأرض وسبب الجاذبية}

الأرض لما جاذبية فما الذي يجذب هذا إذا نزل تحت، قالوا: الجاذبية هي السبب؟ درس علماء الأرض سبب الجاذبية فوجدوا أن باطن الأرض ثقيل، وكلما يكون ثقيلا يكون جذبه قويا، كلما 
نزلنا تحت زادت الأرض ثقلا حتى نصل إلى قرب قلب الأرض، فوجدوا سائلا ثقيلا يدور حول قلب

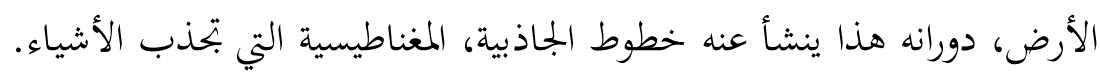

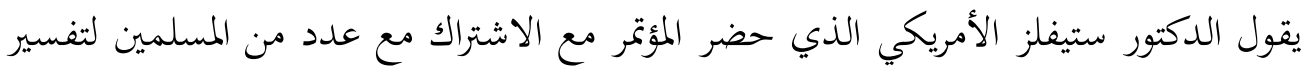

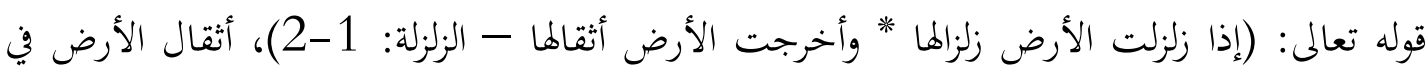

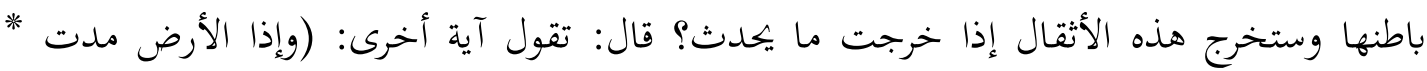
وألقت ما فيها وتخلت - الانشقاق: 3-4)، خرجت الأثقال بَرَّها وألقت ما فيها. أي شيء الترى بعدها؟

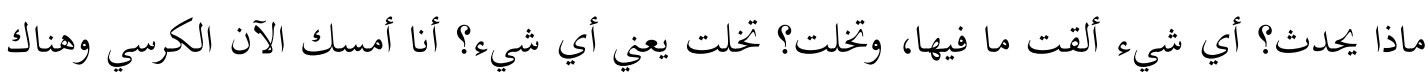

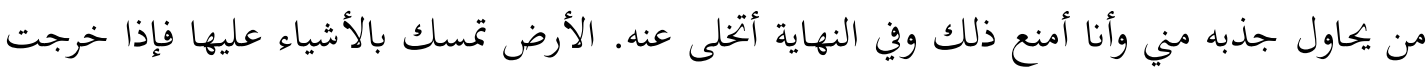

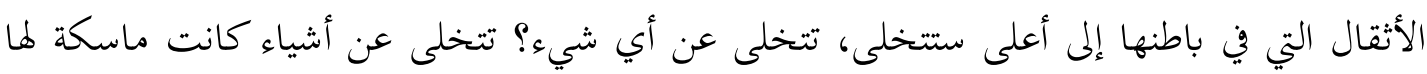

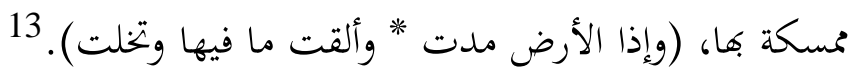
6- إخبار القرآن الكريم عن حقائق الكون

هذه نتائج دراسات معمَّقة وطويلة واستمرت عدة قرون، أدرك بنتيجتها العلماء أن الكون

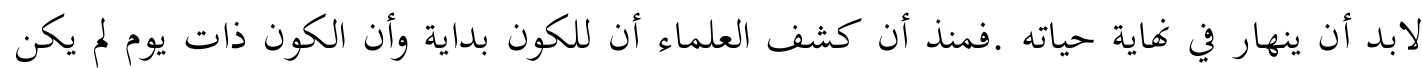

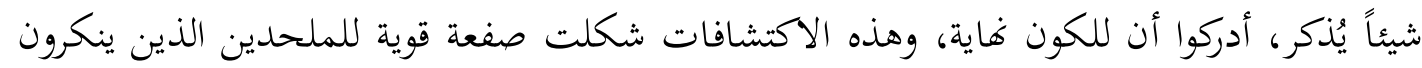

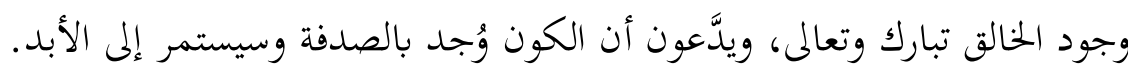

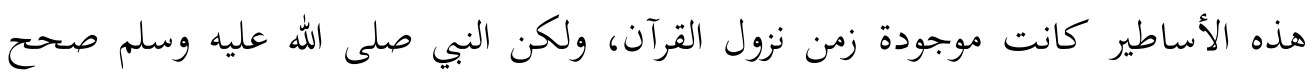
المعتقدات، وأخبر بأن الله هو الذي خلق الكون وأن الكون بدأ من نقطة صغيرة ثم توسَّع ولا يزال

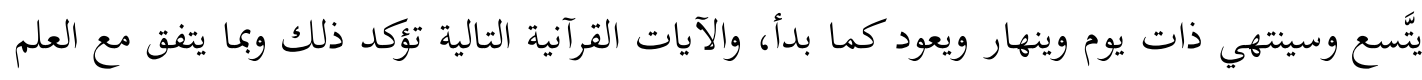

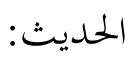

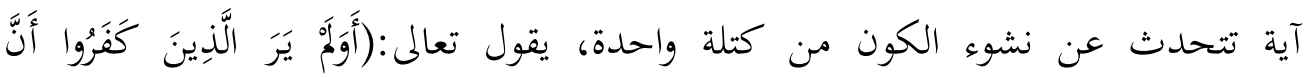

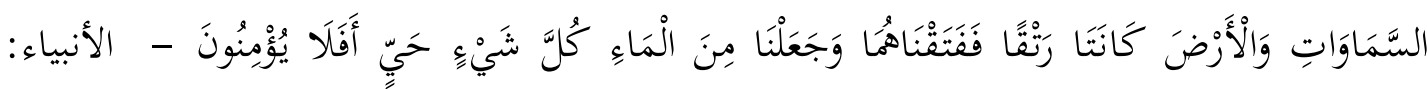

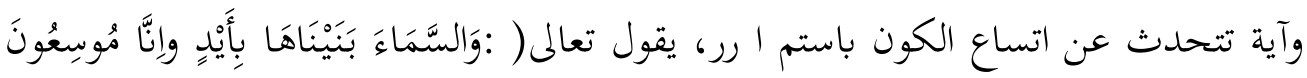

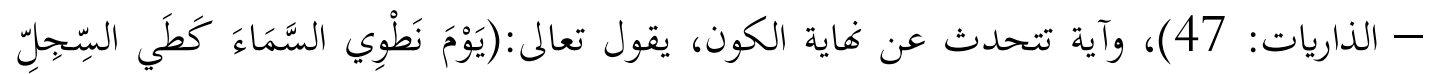

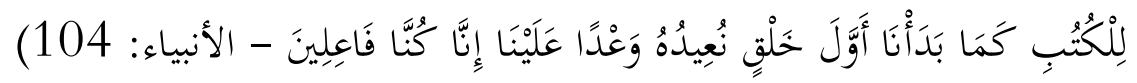


وآيات كثيرة تتحدث عن تشقق السماء وتناثر الكواكب يوم القيامة، بما يتفق مع العلم

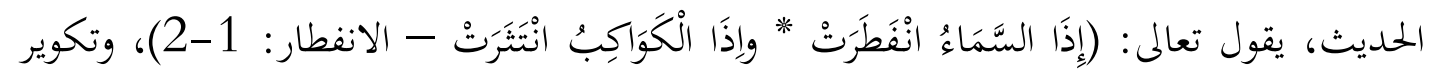

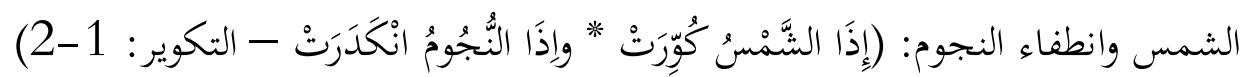
وهكذا فإن هذه الآيات دليل على أن الله هو قائلها، لأن الله تعالى هو الذي خلق الكورن وهو أعلم بمستقبله، ولذلك فقد وضع هذه الآيات في كتابه لتكون شاهداً على صدق هذا الكتاب

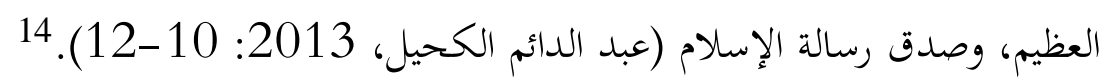

الخاتمة

القرآن الكريم هو معجزة نبينا محمد صلى الله عليه وسلم الباقية إلى قيام الساعة، وقد وعد الله بحفظه ورعايته، فلا يدخله تحريف أو تحويل أو تغيير أو تبديل. والقرآن هو الدلالة العظمى لصدق رسالة نبينا محمد صلى الله عليه وسلم ونبوته، فلن يستطيع أحد أن يأتي بمثله ولو آية واحدة، وهو دليل الحياة الدنيوية والأخروية لأمته صلى الله عليه وسلم. والقرآن معجز في كل شيء، معجز في ألفاظه وآياته وجميع سوره وما تحتويها من نظم وأخبار وشرائع وحقائق وعلوم وغير ذلك. وله شواهد في إعجازه في كل زمان من الأزمان، وين كل جيل من الأجيال، وفي كل علم من العلوم، وفي كل سر من الأسرار، وفي كل اختراع من الاختراعات، وفي كل اكتشاف من الاكتشافات. وهو صالح ودليل في كل زمان ومكان، وكانت صلاحيته ومنافعه للمسلمين خاصة وللناس عامة.

\section{قائمة المصادر والمراجع}

أحمد ديني هداية الله، القرآن الكريم والذكاء اللغوي، مالانق: جامعة مولانا مالك إبراهيم مالانق، الطبعة

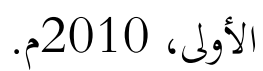

جلال الدين عبد الرحمن السيوطي، الإتقان في علوم القرآن، بيروت: مؤسسة الكتب الثقافية، 1996م. عبد الدائم الكحيل، موسوعة الكحيل للإعجاز العلمي في القرآن والسنة، الجزء 21، 2013م. 
عبد القادر محمد صالح، التفسير والمفسرون في العصر الحديث، حلب: دار المعرفة، الطبعة الأولى، 2003م 1424

عبد المجيد الزنداني، الشيخ، رسائل العلم والإيمان ودلائل الإعجاز في السنة والقرآن، آيات الله في الآفاق، القاهرة: مكتبة القرآن، دون سنة.

عُودة خليل أبو عُودة، التطور الدلالي بين لغة الشعر ولغة القرآن الكريم، الأردن: مكتبة المنار، الطبعة

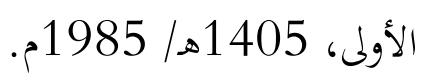

عودة خليل أبو عودة، الدكتور، شواهد في الإعجاز القرآي، دراسة لغوية ودلالية، عمان: المكتبة الوطنية،

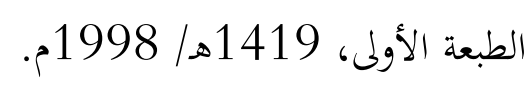

فريد عوض حيدر، الدكتور، علم الدلالة، دراسة نظرية تطبيقية، القاهرة: مكتبة النهضة المصرية، 1999م. محمود إسماعيل صيني، ومختار الطاهر حسين، وسيد عَوض الكريم الدّوش، الدكتور، المعجم السياقي

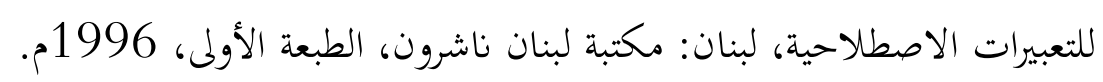


